\title{
Extracellular vesicles from the apoplastic fungal wheat pathogen Zymoseptoria tritici
}

\author{
Erin H. Hill and Peter S. Solomon * ${ }^{*}$
}

\begin{abstract}
Background: The fungal pathogen Zymoseptoria tritici is a significant constraint to wheat production in temperate cropping regions around the world. Despite its agronomic impacts, the mechanisms allowing the pathogen to asymptomatically invade and grow in the apoplast of wheat leaves before causing extensive host cell death remain elusive. Given recent evidence of extracellular vesicles (EVs) — secreted, membrane-bound nanoparticles containing molecular cargo-being implicated in extracellular communication between plants and fungal pathogen, we have initiated an in vitro investigation of EVs from this apoplastic fungal wheat pathogen. We aimed to isolate EVs from Z. tritici broth cultures and examine their protein composition in relation to the soluble protein in the culture filtrate and to existing fungal $\mathrm{EV}$ proteomes.
\end{abstract}

Results: Zymoseptoria tritici EVs were isolated from broth culture filtrates using differential ultracentrifugation (DUC) and examined with transmission electron microscopy (TEM) and nanoparticle tracking analysis (NTA). Z. tritici EVs were observed as a heterogeneous population of particles, with most between 50 and $250 \mathrm{~nm}$. These particles were found in abundance in the culture filtrates of viable $Z$. tritici cultures, but not heat-killed cultures incubated for an equivalent time and of comparable biomass. Bottom-up proteomic analysis using LC-MS/MS, followed by stringent filtering revealed 240 Z. tritici EV proteins. These proteins were distinct from soluble proteins identified in Z. tritici culture filtrates, but were similar to proteins identified in EVs from other fungi, based on sequence similarity analyses. Notably, a putative marker protein recently identified in Candida albicans EVs was also consistently detected in Z. tritici EVs.

Conclusion: We have shown EVs can be isolated from the devastating fungal wheat pathogen Z. tritici and are similar to protein composition to previously characterised fungal EVs. EVs from human pathogenic fungi are implicated in virulence, but the role of EVs in the interaction of phytopathogenic fungi and their hosts is unknown. These in vitro analyses provide a basis for expanding investigations of Z. tritici EVs in planta, to examine their involvement in the infection process of this apoplastic wheat pathogen and more broadly, advance understanding of noncanonical secretion in filamentous plant pathogens.

Keywords: Extracellular vesicles, Zymoseptoria tritici, Wheat disease

\section{Background}

Zymoseptoria tritici is the fungal pathogen responsible for Septoria Tritici Blotch (STB) of wheat. This disease threatens wheat production in the world's temperate cropping regions, causing particularly significant yield

*Correspondence: peter.solomon@anu.edu.au

Division of Plant Sciences, Research School of Biology, The Australian

National University, Canberra 2601, Australia reductions across Europe [1, 2]. STB is a foliar disease, beginning with the germination of $Z$. tritici spores on the leaf surface and hyphal entry into the host tissue via stomata. On penetration, $Z$. tritici hyphae slowly colonise the extracellular spaces of the mesophyll over a long latent period of approximately 8-11 days, depending on the pathogen isolate and wheat cultivar combination $[3,4]$. The pathogen then transitions to necrotrophic growth: host cell death is induced, manifesting as 
necrotic lesions on the leaves and releasing nutrients to fuel fungal growth. This allows the pathogen to produce mature asexual fruiting bodies, pycnidia, that disseminate pycnidiospores and spread infections to adjacent leaves and neighbouring plants [3].

The latent period of $Z$. tritici infection is symptomless and the pathogen is suggested to gain nutrients from its own lipid stores, rather than exploiting host nutrients [5]. At this point, host defences are not strongly induced, putatively due to pathogen evasion or suppression, until the switch to necrotrophy when there is a 'hyperactivation' of defence responses [5]. The molecular events occurring during this latent period and necrotrophic switch remain unclear but it is likely effectorsin the form of proteins or secondary metabolites (SM) and potentially small RNAs (sRNAs) - are secreted to the apoplast and/or adjacent wheat cells to suppress or manipulate host defence responses [5, 6]. Significant genomic, transcriptomic and functional work has aimed to identify and characterise these $Z$. tritici pathogenicity factors, with many studies focusing on proteins with canonical $\mathrm{N}$-terminal secretion signals (or signal peptides (SPs)) that are putatively exported from the cell via the ER-Golgi pathway [5, 7-11]. Despite these efforts, few secreted effector proteins have been shown to contribute to the disease phenotype, likely partly due to the functional redundancy in effector proteins and the quantitative nature of host resistance/pathogen virulence in the wheat-Z. tritici interaction [5, 12-14]. It is arguable that in filtering proteins for canonical SPs in these studies, a subset of effectors or other virulence factors could have been missed, as effectors lacking SPs have been characterised in at least three fungal phytopathogens $[15,16]$. It is also important to recognise that even some proteins with canonical SPs are likely secreted via noncanonical pathways, as shown for effectors in the oomycete Phytophthora infestans and the fungal rice pathogen Magnaporthe oryzae [17, 18]. Given this and the fact that a proportion of the experimentally-defined Z. tritici secretome lacks SPs, it is possible non-canonical pathways may play a role in the secretion of $Z$. tritici virulence factors $[19,20]$. To date, the role of these non-canonical secretory pathways in the $Z$. tritici-wheat interaction is unexplored.

Extracellular vesicles (EVs) are a non-canonical secretion mechanism implicated in cell-cell communication in and between organisms [21]. These vesicles are lipid bilayer-bound structures that carry molecular cargo, including proteins, lipids and nucleic acids. They are secreted from cells to the extracellular space as a heterogeneous population, varying in size, cargo and biogenesis [22]. Recent evidence from plants suggests EVs may be involved in cross-kingdom communication between plants and their microbial pathogens [23, 24]. Arabidopsis thaliana releases EVs to the apoplast that are enriched in defence and stress-associated proteins and 'tiny' small RNAs (sRNAs). These EVs are hypothesised to be involved in defence against the bacterial pathogen Pseudomonas syringae $[25,26]$. Arabidopsis thaliana has also been suggested to secrete EVs carrying sRNAs involved in host-induced gene silencing of genes in the fungal pathogen Botrytis cinerea [23], while EVs from sunflower leaves were implicated in inhibiting the germination and growth of Sclerotinia sclerotiorum ascospores [27].

Fungi also secrete EVs but their role in plant-pathogen interactions has yet to be examined. Fungal EV research has largely focused on Saccharomyces cerevisiae and the human pathogens Candida albicans, Cryptococcus neoformans and Histoplasma capsulatum (recently reviewed in Bielska and May, Bleakley et al. and Silva et al. [2830]); this has led to the description of EVs from these pathogen as 'fungal virulence bags' [31]. To date, EVs have only been isolated from one plant pathogenic fungus, the cotton wilt pathogen Fusarium oxysporum f. sp. vasinfectum (Fov). Fov EVs are phytotoxic on cotton and Nicotiana benthamiana, but their role in the infection lifecycle of the pathogen is unknown [32].

Given the apoplastic lifestyle of $Z$. tritici, we speculated that EVs may be secreted by the pathogen during its colonisation of the apoplast, perhaps to secrete pathogenicity factors or target molecules to neighbouring host cells. To pave the way for these investigations, we aimed to isolate $Z$. tritici EVs produced in vitro and perform preliminary proteomic profiling of $Z$. tritici EV protein cargo. These insights into the secretion and cargo of $Z$. tritici EVs provide a foundation for expanding these investigations in planta and assessing the role of $Z$. tritici EVs in the apoplast during infection of wheat.

\section{Results}

\section{EVs can be isolated from $Z$. tritici cultures}

To determine if $Z$. tritici secretes EVs under in vitro culture conditions, as described for other fungi, we isolated EVs from $Z$. tritici broth cultures using a differential ultracentrifugation (DUC) method adapted from Rodrigues et al. [59] and Thery et al. [60]. We observed particles resembling fungal and mammalian EVs, based on their comparable morphology and size distribution, using transmission electron microscopy (TEM) and nanoparticle tracking analysis (NTA) (Fig. 1). TEM analysis revealed a heterogeneous population of EVs ranging from $<50$ to $>300 \mathrm{~nm}$ in size, with most particles falling between $50-150 \mathrm{~nm}$ and median and mean particle size of $84.0 \mathrm{~nm}$ and $91.8 \mathrm{~nm}(\mathrm{sd} 39.9 \mathrm{~nm})$, respectively. Some particles were $>300 \mathrm{~nm}$ but these were less frequently observed (Fig. 1a, b). NTA corroborated the 

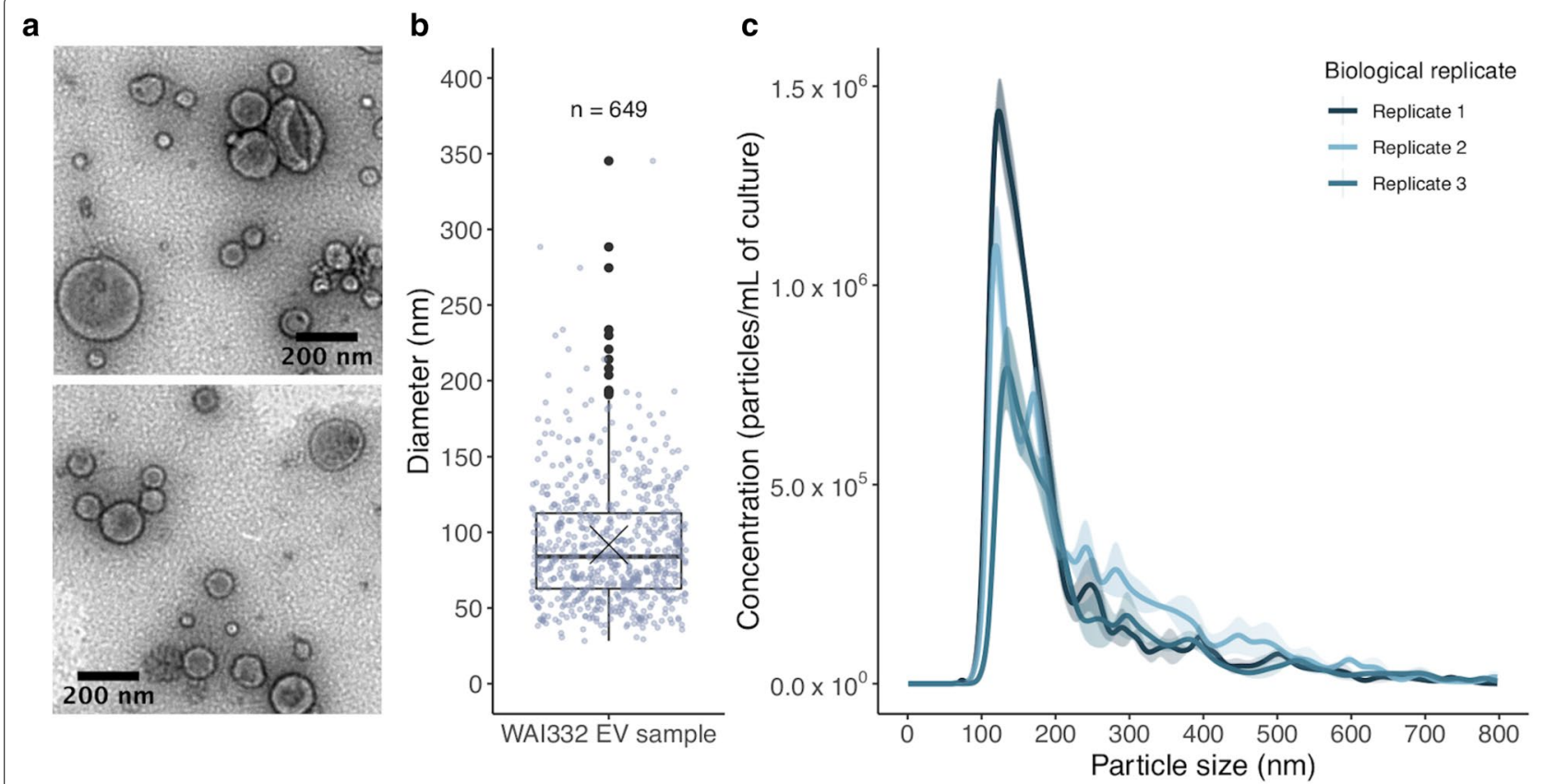

Fig. 1 A heterogeneous population of EVs is secreted by Z. tritici in vitro. $\mathbf{a}, \mathbf{b}$ are representative of several biological replicate EV samples, with (a) showing representative TEM data of 2\% uranyl acetate-stained EV samples. Images were cropped and scale bars added using ImageJ; no other modifications were made. $\mathbf{b}$ Boxplot showing the distribution in EV diameter, measured using ImageJ of the representative EV sample, shown in a. The median particle size was $84.0 \mathrm{~nm}$; the cross represents a mean particle size of ( $91.83 \mathrm{~nm} \pm 39.9 \mathrm{sd}$ ). Each point on the boxplot represents an EV-like particle from the TEM data $(n=649)$. c NTA data showing particle size versus concentration of particles per $\mathrm{mL}$ of fungal culture for 3 biological replicates. The size distributions were averaged across 3 technical replicates and the standard error for each plotted value is indicated with shading. Mean particle size ranged from 168.0-195.2 nm and the modal particle size from 134.13 to $150.3 \mathrm{~nm}$

TEM-derived EV population size distributions, revealing a dominant peak in the particle size distribution between approximately $100-250 \mathrm{~nm}$ (Fig. 1c). The apparent lack of smaller particles represented in the NTA size distribution when compared to the TEM measurements, may be artefactual of NTA systems' known underreporting of particles $<50 \mathrm{~nm}$ and/or the dehydration and shrinkage caused by negatively staining EVs for TEM [21, 33]. $Z$. tritici EV samples typically had a concentration of 0.12 $0.15 \mu \mathrm{g}$ of protein and $1.45-2.43 \times 10^{8}$ particles per $\mathrm{mL}$ of culture filtrate. While $Z$. tritici isolate WAI332 grown in the semi-defined medium Fries 3 was typically used for $\mathrm{EV}$ isolations, we found that EVs could also be isolated from the same isolate cultured in potato dextrose broth and minimal media and from another Australian isolate, WAI321 (Additional file 1: Figure S1).

EVs are described as membrane-bound, cargo-containing particles released by cells. We wanted to confirm the EVs observed in Z. tritici cultures were the product of viable cells rather than membranous artefacts of senescing cells or cell debris. Z. tritici is a heat-labile fungus so we compared the presence of EVs in heat-treated cultures with that of untreated cultures. $Z$. tritici cells were heat-treated after $72 \mathrm{~h}$ of growth and incubated in fresh culture medium alongside viable cultures for a further $72 \mathrm{~h}$, until the latter were of equivalent biomass (Fig. 2, Additional file 2: Table S1). Heat-treated cells were not viable when plated on YSA (data not shown). TEM suggested heat-treated cultures produced samples rich in irregularly-shaped debris, with some EV-like particles observed (Fig. 2b, c). Comparatively, EVs were abundant in the non-heat-treated culture. Nanoparticle tracking analysis indicated particles in the $100-250 \mathrm{~nm}$ range were less concentrated in heat-treated cultures. EVs from untreated cultures had mean and modal sizes ranging from $135.7-168.0 \mathrm{~nm}$ and $109.7-134.1 \mathrm{~nm}$ from two biological replicates, respectively. Particles from heattreated cultures ranged from 125.1-129.3 nm in average size and 93.0-102.5 nm in modal size (Fig. 2d; Additional file 1: Figure S2). We also found EV-like particles were absent from the medium only control, confirming EVs were not an artefact of the semi-defined growth medium or isolation procedure (Fig. 2a, d).

\section{Z. tritici EVs have a protein profile distinct from soluble secreted proteins in the broth culture filtrate}

It is well established that EVs from mammals, fungi, plants and bacteria contain protein cargo so we aimed 

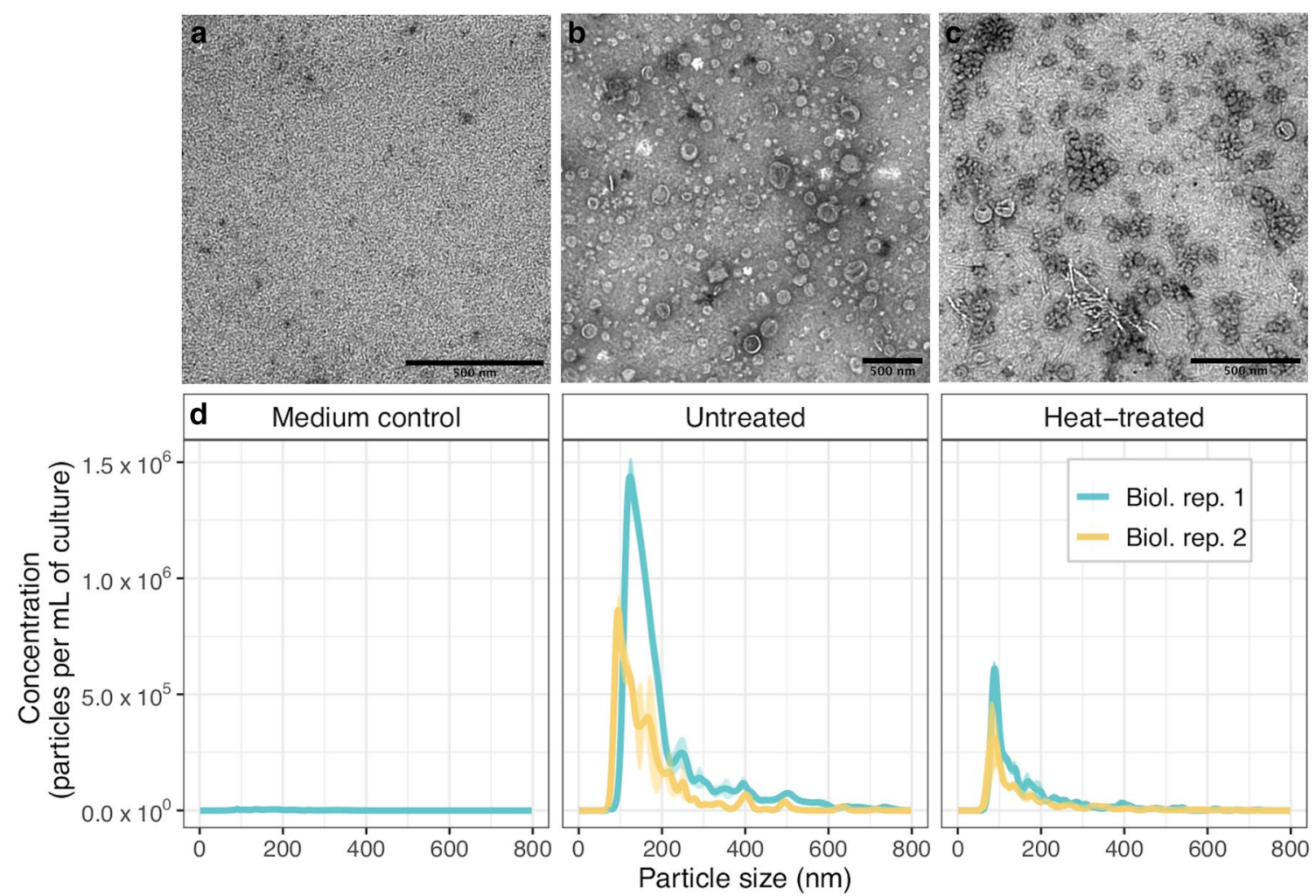

Fig. 2 EVs are abundantly produced by viable Z. tritici cultures but not heat-treated cultures. a-c TEM of samples prepared using differential ultracentrifugation from a medium-only control culture, untreated and heat-treated Z. tritici cultures, respectively. Scale bars represent $500 \mathrm{~nm}$. d Nanoparticle tracking analysis of the corresponding samples: plots represent the mean particle concentration per $\mathrm{mL}$ of culture filtrate versus particle size $(\mathrm{nm})$, with each size distribution averaged over three technical replicates. The mean and modal particle size for the untreated condition ranged from 135.7-168.0 nm and 109.7-134.1 nm, respectively. Mean and modal size of particles in the heat-treated condition were 125.1$129.3 \mathrm{~nm}$ and $93.0-102.5 \mathrm{~nm}$, respectively. Shading along the size distributions represents the standard error of each plotted value

to profile the protein content of $Z$. tritici EVs released under in vitro growth conditions using bottom-up proteomics. From five biological replicate EV samples we identified 240 high-confidence $(\mathrm{HC})$ proteins consistently detected using LC-MS/MS; these proteins were identified using a minimum of two unique peptides in at least $4 / 5 \mathrm{EV}$ replicates (Table 1 ). The full list of proteins is provided in Additional file 2, Table S2. We made qualitative presence/absence comparisons of protein content in EV samples with soluble secreted proteins (SS); the SS fraction was prepared from the supernatant separated from EVs by UC at $100,000 \times g$. This supernatant was again centrifuged at $120,000 \times g$ to remove remaining $E V s$ and insoluble debris. LC-MS/MS analysis of the SS fraction identified $79 \mathrm{HC}$ proteins (detected in at least $2 / 3$ biological replicates).

Of the $240 \mathrm{HC}$ EV proteins, 210 were present only in the EV samples, while $49 \mathrm{SS}$ proteins were unique to SS samples and 30 proteins were shared between the fractions (Fig. 3a, Additional file 2: Table S3). Whether the presence of proteins in both fractions is due to insufficient purification of EVs, contamination from disrupted EVs, or the secretion of proteins via EVs and canonical secretion pathways will require further investigation. Given this, we have focused on HC proteins unique to either the EV or SS fractions; values reported will be in reference to these $\mathrm{HC}$, fraction-specific protein groups.

To probe potential differences in the characteristics of proteins in the EV and SS fractions we identified those with canonical secretion signals (SPs) and transmembrane domains (TMDs) or glycosylphosphatidylinositol-(GPI) anchors, the latter being features of membrane-associated proteins (Table 1; Additional file 2: Table S2, S3). The proportion of proteins with canonical SPs was greater (77.6\%) in the HC SS fraction than in EVs (6.7\%). The presence of proteins without a SP in yeast and filamentous fungal culture filtrates has been reported and may result from non-canonical secretion mechanisms $[15,34,35]$. Proteins lacking SPs have been identified in proteomic analyses of both in planta and in vitro $Z$. tritici secretomes $[19,20,36]$. EV 
Table 1 Characteristics of proteins identified in Z. tritici EV samples and the soluble secreted fraction

\begin{tabular}{|c|c|c|}
\hline Proteins identified using LC-MS/MS & EV proteins & $\begin{array}{l}\text { Soluble } \\
\text { secreted } \\
\text { proteins (SS) }\end{array}$ \\
\hline Biological replicates & 5 & 3 \\
\hline Total proteins identified & 771 & 99 \\
\hline High confidence $(\mathrm{HC})$ proteins $^{1}$ & 240 & 79 \\
\hline HC proteins unique to sample type ${ }^{2}$ & $210(100 \%)$ & $49(100 \%)$ \\
\hline Proteins with signal peptides & $14(6.7 \%)$ & $38(77.6 \%)$ \\
\hline $\begin{array}{l}\text { Proteins with transmembrane } \\
\text { domains/GPI-anchors }{ }^{3}\end{array}$ & 15 (7.1\%) & $1(2.0 \%)$ \\
\hline Putative Cazymes & $7(3.3 \%)$ & $6(12.2 \%)$ \\
\hline Putative proteolytic enzymes & $6(2.5 \%)$ & $3(6.1 \%)$ \\
\hline Predicted effectors ${ }^{4}$ & $17(8.1 \%)$ & $16(32.7 \%)$ \\
\hline Median protein size & 426 aa & 257 aа \\
\hline
\end{tabular}

1 Proteins were high-confidence if present in $\geq 4 / 5 \mathrm{EV}$ biological replicates or $\geq 2 / 3$ SS replicates, with $\geq 2$ unique peptides detected

2 Protein counts and percentages in the following rows are in reference to the subset of HC proteins detected only in EVs or SS fractions; proteins detected in both fractions were excluded from these counts

${ }^{3}$ Transmembrane domains predictions by TMHMM were included when more than one domain predicted, or if only one was predicted, this was not in the first 60 amino acids

${ }^{4}$ Effector count includes proteins predicted as effector by both v1.0 and v2.0 of EffectorP

proteins largely lacked SPs, aligning with previous analyses of fungal EV protein cargo [37]. EVs had more predicted membrane-associated proteins (7.1\%) compared to the secreted fraction $(2.0 \%)$.

We also aimed to identify proteins potentially important for virulence, such as hydrolytic enzymes like cell wall degrading enzymes (CWDEs), proteases and effector proteins, in EV and SS fractions. The gene and protein expression profiles of these virulence-associated proteins induced in vitro may not reflect their expression during Z tritici in planta infection. However, some in vitro growth conditions, such as Fries medium, can induce the expression of virulence-associated genes, including effectors and secondary metabolites, of plant pathogenic fungi $[38,39]$. We found that hydrolytic enzymes-including proteins with carbohydrate active enzymatic domains (CAzymes) or peptidase protein domains-constituted a larger proportion of SS proteins $(12.2 \%$ and $6.1 \%$, respectively) compared to EV proteins (3.3\% and $2.5 \%)$. Similarly, more SS proteins were predicted to be effectors by EffectorP (32.7\% vs $8.1 \%$ in EVs) (Table 1, Additional file 2: Table S4). Putative effectors in SS samples were largely uncharacterised proteins. In comparison, EVassociated predicted effectors often had high sequence similarity to characterised proteins in the NCBI/Uniprot database, for example, several ribosomal subunit proteins. It remains to be seen if these are spurious effector predictions, or a true reflection of their importance for virulence in wheat.

To gauge an approximate idea of the proportion of EV proteins involved in different cellular processes, proteins were assigned putative functional annotations based on predicted domains and sequence identity to characterised proteins in the Uniprot and NCBI non-redundant protein databases (Fig. 3, Additional file 2: Table S2). Based on this categorisation, EVs were distinct from the SS fraction in their protein cargo. Over $50 \%$ of SS proteins were uncharacterised proteins compared to $7 \%$ of EV proteins (Additional file 2: Tables S2, S3). Approximately a quarter of EV proteins assigned a functional description were putatively associated with sugar, lipid and other metabolic processes (24.3\%) and 18.6\% involved in amino acid metabolism and protein homeostasis/metabolism. This included putative heat-shock proteins (Hsp60, Hsp82, Hsp90 co-chaperone), a protein disulphide isomerase, and translational machinery such as translation elongation (EF-2, EF-1-gamma, EF-3) and initiation factors. Similarly, ribosomal subunit proteins constituted $15.7 \%$ of EV proteins. The proportion of proteins in these categories were comparatively low in SS samples. Interestingly, of the 30 proteins identified in both SS and EV fractions, most were associated with carbohydrate and lipid metabolism (23.3\%) or carbohydrate hydrolytic activity (20\%), or were uncharacterised (36.7\%) (Fig. 3, Additional file 2: Table S3).

Given the membranous nature of EVs we expected a proportion of proteins to be membrane associated: $6.7 \%$ of proteins were putatively membrane associated and included $\mathrm{ABC}$ transporters and other ATPase domaincontaining proteins. Proteins involved with endo- and exocytosis or the endomembrane system $(3.3 \%$ of proteins) included clathrin, a putative t-SNARE protein, an ADP-ribsoylation factor and a Sar1 GTPase-like protein. Actin, tubulin and fimbrin were among 7 proteins (3.3\%) associated with the cytoskeleton. Proteins in these categories were largely absent from the SS fraction, with the exception of a GPI-anchored uncharacterised protein.

\section{Z. tritici EV proteins overlap with proteins identified in other fungal EVs}

We looked for similar proteins in the cargos of other fungal EVs to determine the overlap of $Z$. tritici EVs with other fungi. We used the sequences of fungal EV proteins from previous proteomic studies of the human pathogenic fungi C. albicans, C. neoformans, $H$. capsulatum and Paracoccidioides brasiliensis; the cotton pathogen Fov; and S. cerevisiae (total $\mathrm{n}=6648$ ). The datasets and articles referred to are summarised in the additional files (Additional file 2: Table S5). $77.8 \%$ of these proteins were assigned to 1453 orthogroups (OGs), with the 


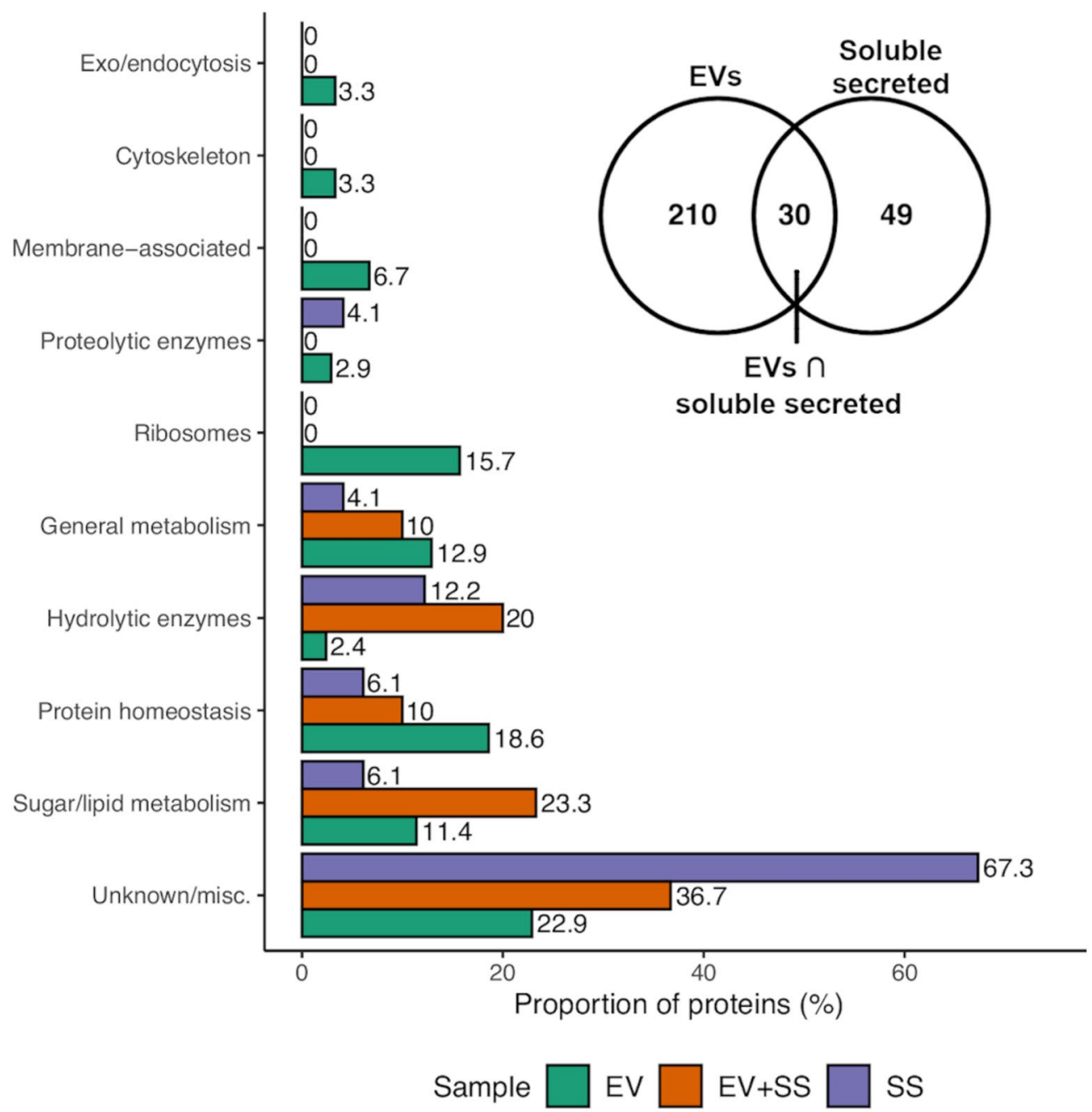

Fig. 3 Functional classification of EV and soluble secreted (SS) proteins. Proteins were manually classified according to sequence similarity to proteins in the Uniprot database and the presence of conserved protein domains. The inset venn diagram shows the overlap of the EV and SS protein sets compared in the bar chart; proteins identified in both EV and SS fractions, denoted EV + SS, are also represented in the bar chart

majority of OGs (88.9\%) containing proteins from more than two species (Fig. 4a). Only 3 OGs included similar EV proteins from all 7 species (Fig. 4a, c). These consisted of peptidyl-prolyl cis-trans isomerase proteins (OG9), plasma membrane ATPases (OG12) and ADPribosylation factors (ARFs) (OG18), respectively, the latter including three ARFs characterised in yeast as proteins associated with vesicle trafficking (Additional file 2: Table S6). $95.5 \%$ of $Z$. tritici EV proteins were assigned to 177 OGs (12.2\%), of which 2 were species-specific. $Z$. tritici $\mathrm{EV}$ proteins were most frequently grouped with similar proteins from S. cerevisiae, C. albicans and Histoplasma, though this is likely a reflection of the larger size of the EV proteomes currently defined for these fungi, compared to the P. brasiliensis or Fov proteomes (Fig. 4b, c). Orthogroups shared by Z. tritici and Fov exclusively were of interest, given their shared plant pathogenic lifestyles. Two groups of orthologous proteins were exclusive to these pathogens and consisted of subtilisin-like peptidases (OG1244) and peroxidase-catalase like proteins (OG765). Only $14 Z$. tritici EV proteins were not assigned to an OG or grouped in a species-specific OG, suggesting significant similarity in the proteins identified in Z. tritici EVs and other fungal EVs characterised to date.

\section{The proposed fungal EV protein marker Sur7 is consistently detected in Z. tritici EVs}

A recent comprehensive study of potential marker proteins for Candida albicans EVs showed that the Sur7family members CaSur7 and Evp1 were promising 

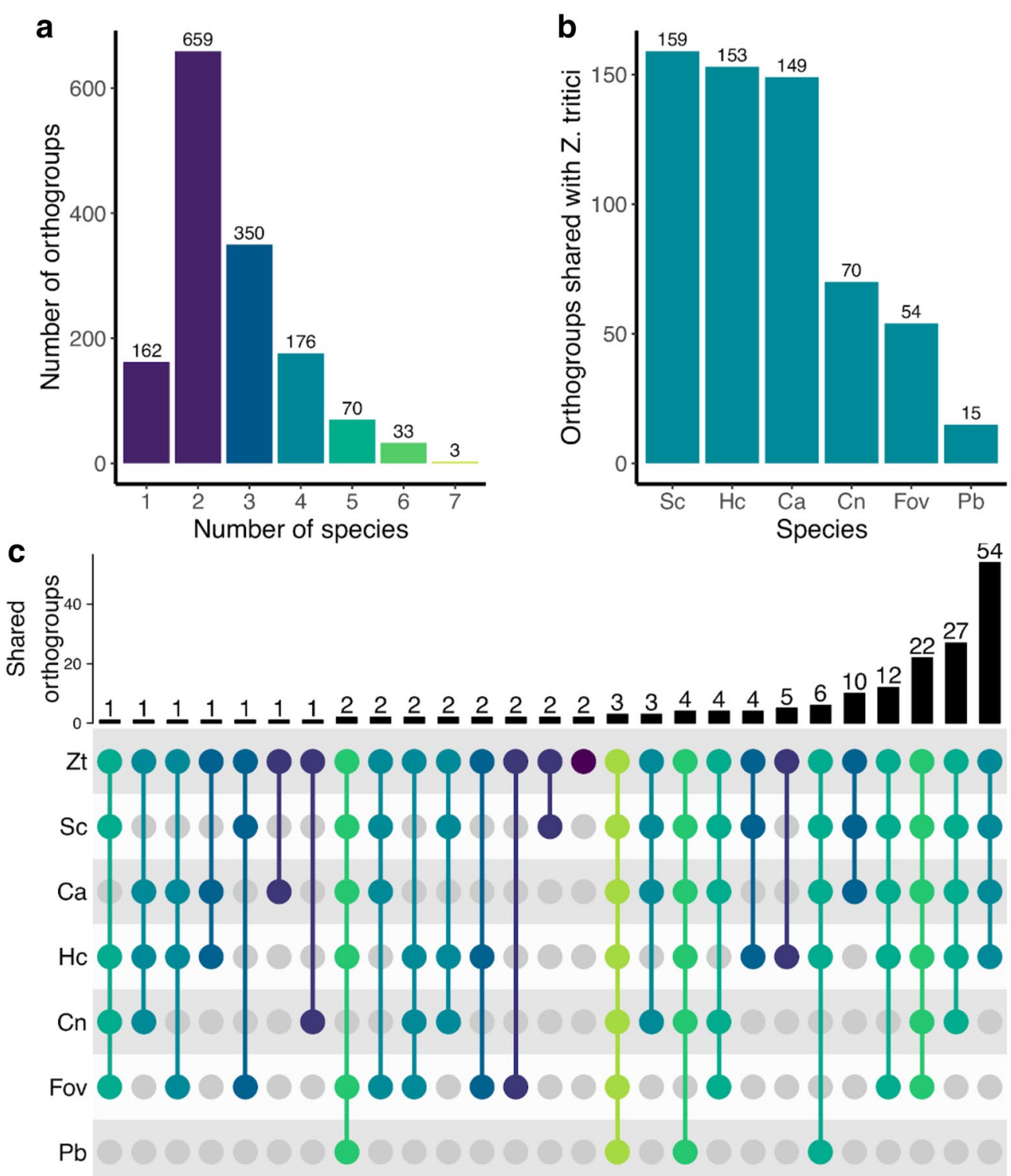

Fig. 4 Z. tritici EV proteins group with EV proteins from other fungi based on sequence similarity. The fungi compared in the plot are S. cerevisiae (SC), H. capsulatum (HC), C. albicans (Ca), C. neoformans (Cn), F. oxysporum f. sp. vasinfectum (Fov) and P. brasiliensis (Pb). Proteins previously identified in fungal EVs were grouped into orthologous groups using Orthofinder; only intersections including Z. tritici were represented in the plot. a shows the number of orthogroups shared by all species; for example, 3 orthogroups are shared by all seven species. $\mathbf{b}$ Bar plot showing the number of orthogroups shared by Z. tritici and each fungal species. The intersection of Z. tritici orthogroups with those of the other fungi is represented with an Upset plot, shown in c. The bottom panel plots the intersections of orthogroups from each species. Each row represents a species and each column indicates which combination of species share $x$ number of orthogroups. Dark, connecting dots indicate which species in a column share orthogroups. The bar plot at the top represents the size of the intersection, or how many orthogroups are shared by each combination of species. For example, 48 orthogroups are shared by Z. tritici $(Z t)$ and $S c, H c$ and $C a$, while two orthogroups are species-specific to Zt

markers for C. albicans EVs [40]. We found a putative CaSur7 homologue, here referred to as $Z t S u r 7$, was consistently detected in Z. tritici EV samples from in vitro cultures (Additional file 2: Table S2). ZtSur7 has a 28.3\% pairwise sequence identity with CaSur7, a shared Sur7 protein domain (L12-I207) and four predicted TMDs with a similar topology to the $C$. albicans protein (Additional file 1: Figure S2a). This protein was not detected in secreted samples and was only detected in $2 / 5$ cell lysate samples (CL), which we analysed alongside the $Z$. tritici EV samples (a list of proteins identified in CL samples is available in additional file 2, Table S7). This aligns with 
the criteria Dawson et al. used to identify this protein as a fungal EV protein marker in C. albicans, which was based on recommendations for marker proteins by the International Society of Extracellular Vesicles [40, 41]. Analysis of RNA-seq evidence from a previous study describing Z. tritici WAI332 gene expression in planta (Wang et al., under review) found the $Z t S u r 7$ gene is expressed during infection of wheat at 9- and 14-days post infection (Additional file 1: Figure S2b).

Dawson et al. also proposed 7 negative marker proteins for C. albicans EVs. Negative markers are needed for confirming EV cargoes are distinct from the general contents of the cell or plasma membrane, as outlined by Thery et al. $[40,41]$. We identified putative orthologous proteins in $Z$. tritici with a reciprocal best-hit blastp search. Orthologues of five of these C. albicans proteins-ABP1, APR1, Cyp1, LAP41 and LPD1-were identified in $80 \%$ of $Z$. tritici cell lysate (CL) samples (Additional file 2: Tables S7, S8). These proteins were not consistently identified in $Z$. tritici EVs. Together, this suggests Sur7 is an EV-associated protein and potential marker in $Z$. tritici as well as C. albicans, while $Z$. tritici proteins orthologous to the aforementioned negative protein markers, may also be applicable for studies of $Z$. tritici EVs in vitro.

\section{Discussion}

While EVs from mammalian cell lines have been widely studied, an understanding of fungal EVs is lacking, particularly in the context of plant-pathogen interactions. Recently, the first report of EVs from the cotton pathogen Fov suggested its EVs may be implicated in pathogenesis [32]. We have now reported our study of EVs from an agronomically-significant wheat pathogen, $Z$. tritici. This is the first description and proteomic analysis of $Z$. tritici EVs secreted under in vitro conditions and it is anticipated this initial step will provide a foundation for future studies of Z. tritici EVs in the pathogen's infection of wheat.

Our findings show Z. tritici produces small $(<100 \mathrm{~nm})$ and some larger EVs $(\sim 100-300 \mathrm{~nm})$ that are consistent with the EV populations isolated from other fungi [30]. Similarly, our proteomic analysis of $Z$. tritici EVs suggests the protein cargo broadly overlaps with existing fungal EVs proteomes, given the majority of proteins identified shared orthogroups with EV proteins from more than one fungal species. This observation, combined with the fact that the presence of EV particles appears reduced in heattreated $Z$. tritici cultures-a result seen in other fungi $[28,42,43]$-consolidates the hypothesis that $Z$. tritici EVs are actively secreted by cells rather than being randomly-shed membranous artefacts [44]. To this end, $Z$. tritici EVs also contain some proteins consistently associated with mammalian EVs, including the cytoskeletal components actin and tubulin; proteins implicated in signal transduction such as 14-3-3 domain-containing proteins; clathrin, which is involved in mammalian EV biogenesis as well as clathrin-mediated endocytosis; and heat-shock proteins, including Hsp70 family and Hsp90 proteins $[21,45,46]$. Taken together, the overlap of $Z$. tritici EV protein cargo with that of other fungal EVs and mammalian EVs provides confidence these are similar to the EVs released by other fungi.

We identified $210 Z$. tritici EV proteins that were present in at least $4 / 5$ biological replicates. This mirrors the number of proteins identified in earlier proteomic studies of EVs from C. neoformans, C. albicans and H. capsulatum, which range from $\sim 50$ to 200 proteins [31, 42, 47]. It is significantly fewer than the number of proteins identified in most recent studies of EVs from Fov (482 EV proteins) [32], S. cerevisiae (3133) [28] and C. albicans (from 729 to 1202 across different strains and morphologies in Zarnowski et al. [52] and Dawson et al. [40]). Based on the latter studies which identified $>400$ proteins using stringent filtering thresholds and multiple biological replicates, the results presented here are likely an underestimation of the $Z$. tritici proteome. More comprehensive proteomic profiling of $Z$. tritici EVs from different fungal growth conditions or different strains may help to expand on the $Z$. tritici $\mathrm{EV}$ proteome defined here.

The proteins identified in $Z$. tritici EVs were grouped into functional categories based on sequence identity to characterised proteins and/or the presence of protein domains. The majority of proteins were putatively associated with cellular metabolic processes, particularly lipid and carbohydrate metabolism, and protein homeostasis (e.g. protein translation and folding) and amino acid metabolism. This broadly reflects the annotated functions associated with EV proteins in other fungi, particularly recent observations that fungal EVs are consistently enriched in proteins associated with protein and carbohydrate metabolism and are implicated in cell wall maintenance and remodelling [28, 37].

As with other fungal EVs, an Hsp70 family protein was present in Z. tritici EVs, with two others present in both EVs and the secreted fraction. Of the latter, one protein (evm.model.chr_10.464) had the highest sequence identity (86\%) to the conserved Hsp70 chaperone in the model filamentous fungus Neurospora crassa. The presence of $\mathrm{Hsp} 70$ in EV and EV-free fractions was similarly observed in the human pathogen $P$. brasiliensis, and has speculated to be due to secretion via multiple pathways [48]. Hsp70 is a classical mammalian EV marker [45] and was suggested as a potential fungal EV marker (in combination with other markers) given its apparent ubiquity in fungal EVs [32, 37]. Whether the co-occurrence of Hsp70-like proteins in EV and the soluble supernatant 
in Z. tritici is the result of contaminated sample preparation, or because the protein is secreted by noncanonical and canonical secretory pathways remains to be seen. It suggests Hsp70 is unlikely to be a valid marker in this fungus until the nature of this co-occurrence is investigated.

Fungal EVs are implicated in virulence, evidenced by the presence of virulence-associated cargo and immunogenicity of EVs from some human pathogenic fungi. For example, EVs from C. neoformans, a pathogen of immunocompromised people, secretes EVs containing the major virulence proteins urease and laccase and the capsular polysaccharide glucuronoxylomannan (GXM) [31]. Another opportunistic human pathogen C. albicans secretes EVs carrying proteins associated with adhesion to host cells [37]. C. albicans EVs have also been shown to stimulate nitric oxide and cytokine production in immune cells and internalisation by bone-marrow derived macrophages [49]. Given this, EVs from human pathogenic fungi have been referred to as 'virulence bags' [31]. The role of EVs in the virulence of plant pathogens is unknown, although a recent analysis Fov EVs found they contained secondary metabolite (SM) biosynthetic proteins and an uncharacterised polyketide. This, combined with phytotoxic activity of the EVs in cotton and Nicotiana benthamiana leaves, led the authors to speculate on a role of Fov EVs in pathogenesis [32].

Similarly, we looked for proteins potentially implicated in pathogenesis but found no strong effector candidates or SM proteins associated with Z. tritici EVs. While some EV proteins were predicted to be effectors by the machine learning-based software EffectorP, most of these had sequence homology to highly conserved proteins, for example, $40 \mathrm{~S}$ and $60 \mathrm{~S}$ ribosomal proteins and a small COPII coat GTPase Sar1-like protein (involved in COPII complex required for endoplasmic reticulum transport vesicle assembly). Given fungal effectors are generally, though not always, uncharacterised with little sequence homology to other proteins, we suspect these predicted EV protein 'effectors' are likely false positives. In regards to the lack of SM-associated in Z. tritici EVs, it may be the presence of these in Fov EVs reflects the rich mycoand phytotoxin repertoire of Fusarium spp. [50], rather than being a ubiquitous feature of fungal EVs. This will only be elucidated with a broad analysis of proteomes and metabolomes of EVs from fungal phytopathogens. We also looked for proteases and CAzymes, given their importance in the lifestyle of plant pathogens, but these were also not prevalent in EVs relative to the secreted fraction.

We found a lack of obvious pathogenicity-associated proteins in in vitro-produced $Z$. tritici EVs, but this does not dismiss a possible role for EVs in planta during the pathogen's infection of wheat. It is hard to speculate on this using these data given the EV protein cargo is likely very different in planta. The gene expression profiles of Z. tritici in planta and in vitro are distinct [5]. While some in vitro culture conditions like Fries medium can induce the expression of pathogenesis-associated genes in plant pathogenic fungi, the conditions we have used here cannot effectively simulate those the pathogen would experience in planta. This is particularly significant as mammalian EV cargoes typically reflect the state of the cell of origin and are influenced by changes in the cellular environment [51]. Similarly, the protein composition of fungal EVs has been shown to vary depending on the morphology of the cells and nutrients available in the environment. For example, protein cargo was distinct when EVs from the biofilm and planktonic form of C. albicans were compared [52], while the nutrient composition of culture media was found to influence EV release and protein composition in $H$. capsulatum [53]. $Z$. tritici grows as blastospores, a yeast-like form, in vitro but switches to hyphal growth during colonisation of the wheat apoplast [54]. Hyphal growth can be induced in cultures under nutrient-limited conditions and is linked to transcriptional changes, such as the increased expression of putative effectors, that reflect the in planta expression of virulence-associated genes [55]. A comparison of EVs from hyphal and blastospore morphologies in vitro may provide more insight into the proteins associated with EVs in planta. It is likely only studies of EVs isolated from the wheat apoplast during $Z$. tritici infection of susceptible and resistant cultivars that will reveal a role for EVs in pathogenesis.

Our understanding of the biological function of fungal EVs has been hampered by the lack of fungal specific EV markers. Markers are an essential quality control for EVs and can be used for immunoaffinity-based purification or labelling [41]. Dawson et al. [40] recently defined a set of potential positive and negative protein markers for $C$. albicans EVs, including the fungal specific transmembrane protein Sur7. Sur7 has been characterised as a plasma membrane protein in C. albicans and S. cerevisiae that localises to defined microdomains known as the membrane compartment of Can1 (MCC) and is required for proper cell wall and plasma membrane composition and organisation [56-58]. In this study, a Sur7 homologue ( $Z t$ Sur7) was consistently identified in Z $Z$. tritici EVs, suggesting its use as an EV marker may be applicable to other fungi. The validity of Sur7 proteins as an EV marker for fungal plant pathogens in the context of infection will depend on Sur7 being present in EVs in planta. That the $Z t S u r 7$ gene is expressed in planta at early and late infection timepoints is promising, but further studies are needed to confirm the protein is loaded into EVs in 
this context. Given the fungal specific nature of this protein, it may provide a valuable resource for the separation of wheat- and Z. tritici-derived EVs from the apoplast, in combination with plant EV markers PEN1 and TET8, described by Cai et al. [23] and Rutter and Innes [25].

\section{Conclusions}

In summary, we have reported the first evidence of EVs produced by the devastating wheat pathogen, $Z$. tritici. The morphology and protein composition of these EVs reflect that of previously characterised fungal EVs. While EVs have been shown to have a role in the virulence of human pathogens, their contribution to the lifestyle of plant pathogens is still unknown. It is tempting to speculate about the role of EVs in the Z. tritici-wheat interaction: are they a vehicle for the non-canonical secretion of effectors to the apoplast and/or host cells? Are EVs taken up by wheat cells and if so, how? Are Z. tritici EVs involved in microbial competition in the host? Further study of EVs in Z. tritici, using tools like the marker Sur7, will advance our knowledge of the disease lifecycle of this cryptic, apoplastic wheat pathogen and more broadly, our understanding of noncanonical secretion mechanisms in plant pathogens.

\section{Materials and methods}

\section{Fungal growth conditions}

Z. tritici isolate WAI332 was grown from glycerol stocks on yeast sucrose agar (YSA) for -4 days at $22{ }^{\circ} \mathrm{C}$ under a 12-h light/dark cycle. Cells scraped from agar medium were used to inoculate $100 \mathrm{~mL}$ of Fries 3 broth in $250 \mathrm{~mL}$ conical flasks to a final concentration of $2 \times 10^{5}$ blastospores $/ \mathrm{mL}$ and cultured for $72-\mathrm{h}$, shaking at $140 \mathrm{rpm}$ $\left(22{ }^{\circ} \mathrm{C} ; 12\right.$-h light/dark cycle). At $72 \mathrm{~h}$ culture $\mathrm{OD}_{600}$ was measured to confirm growth between replicate cultures was consistent.

\section{EV isolation by differential ultracentrifugation (DUC)}

EVs were isolated from broth cultures using methods adapted from Thery et al. and Rodrigues et al. [59, 60]. $Z$. tritici cells were removed from broth cultures by centrifugation at $4500 \times g$ for $25 \mathrm{~min}$ in a benchtop centrifuge. Culture supernatant was centrifuged at $15,000 \times g$ $\left(4{ }^{\circ} \mathrm{C}\right)$ for $45 \mathrm{~min}$ in an Avanti J series High Performance centrifuge (Beckman coulter) with a JA 14.50 rotor to remove cell debris. Supernatant was carefully removed and passed through a $0.45 \mu \mathrm{m}$ MF-Millipore membrane filter using vacuum filtration. EVs were pelleted from the culture filtrate by ultracentrifugation for $75 \mathrm{~min}$ at $100,000 \times g$ and $4{ }^{\circ} \mathrm{C}$ in open-top Ultra Clear $38.5 \mathrm{~mL}$ tubes (Beckman coulter, 344058) using an SW 32 Ti swinging bucket rotor and Optima XPN ultracentrifuge (Beckman Coulter). Supernatant was removed completely and the EV pellet washed with $1 \mathrm{X}$ phosphate buffered saline (PBS), pH 7.4 (filter sterilised with $0.22 \mu \mathrm{m}$ membrane), by ultracentrifugation at $100,000 \times g$ (75 min, $4{ }^{\circ} \mathrm{C}$ ). The EV pellet was resuspended in 50 to $100 \mu \mathrm{L}$ of $1 \mathrm{X}$ PBS, pH 7.4 and protein content measured using the Qubit $^{\mathrm{TM}}$ protein assay kit. EV samples were flash-frozen with $\mathrm{LN}_{2}$ and stored at $-80^{\circ} \mathrm{C}$. This process was repeated with a Fries3-only control to confirm EVlike particles were not an artefact of the growth medium.

\section{Heat-treatment of $Z$. tritici broth cultures}

To test if EVs were a product of dead or dying cells cultures of $Z$. tritici in Fries 3 medium (inoculated to a final concentration of $2 \times 10^{5}$ blastospores $/ \mathrm{mL}$ ) were grown for $72 \mathrm{~h}$ and the $\mathrm{OD}_{600}$ measured. Cells were pelleted gently by centrifugation $\left(3000 \times g, 4{ }^{\circ} \mathrm{C}, 10 \mathrm{~min}\right)$, washed three times with fresh culture medium and heated at $55^{\circ} \mathrm{C}$ for $1 \mathrm{~h}$. Cells were pelleted, washed once and resuspended in $100 \mathrm{~mL}$ of fresh Fries 3 medium. A small aliquot of heat-treated cells was plated on YSA to confirm cells were not viable. Heat-treated cultures were incubated for $72 \mathrm{~h}$, alongside untreated $Z$. tritici cultures, prepared as described above. At $72 \mathrm{~h} \mathrm{EVs} \mathrm{were} \mathrm{isolated} \mathrm{from}$ heat-treated and untreated cultures.

\section{Transmission electron microscopy (TEM)}

EV samples were negatively stained for TEM imaging. Carbon-coated copper 200 mesh TEM grids were glow discharged (45 s; 15 milliamps) and incubated with $3 \mu \mathrm{L}$ of EV sample for $1 \mathrm{~min}$. Excess sample was blotted from grids with Whatman ${ }^{\circledR}$ grade 1 qualitative filter paper (GE Healthcare). Grids were briefly washed by floatingsample-side down-on drops of distilled water, blotted and floated on $20 \mu \mathrm{L}$ drops of $2 \%$ uranyl acetate for $45 \mathrm{~s}$. Excess stain was blotted and grids dried before visualising with a Hitachi HA7100 transmission electron microscope, operated at $100 \mathrm{kV}$. All microscopy work was conducted at the Advanced Imaging Precinct of Microscopy Australia at The Australian National University.

\section{Nanoparticle tracking analysis}

Size distribution and particle concentration of EV samples were determined using a NanoSight NS300 fitted with a blue laser $(405 \mathrm{~nm})$ with NanoSight NTA software version 3.3 (Malvern Panalytical). EV samples were diluted 50-200 times using 1X PBS, pH 7.4 filtered with a $0.02 \mu \mathrm{m}$ pore size syringe filter (GE Healthcare). Samples were diluted so less than 100 trackable particles were detected in each video frame. Samples were injected into the flow cell at a flow rate of 40 units. Six 30 s captures were taken in triplicate for each sample, with a camera level of 12-14. For video analysis a detection threshold of 10 was used, with the minimum tracking distance set 
to 'Auto'. The flow cell was flushed with filtered 1X PBS $\mathrm{pH} 7.4$ between samples, until no light scattering was detected. The size distributions generated by the NTA v3.0 software were averaged over technical replicates and plotted using ggplot2 in R [61].

\section{Bottom-up proteomics using LC-MS/MS}

In preparation for LC/MS-MS, EV samples were pelleted and washed with $1 \mathrm{X}$ PBS $\mathrm{pH} 7.4$ using ultracentrifugation $\left(100,000 \times g, 75 \mathrm{~min}, 4{ }^{\circ} \mathrm{C}\right)$ and resuspended in 100 $\mu \mathrm{L}$ of $1 \mathrm{X}$ PBS $\mathrm{pH}$ 7. A volume of EVs equivalent to $4 \mu \mathrm{g}$ of protein was disrupted with sodium dodecyl sulfate (SDS) at a final concentration of $1 \%$ and gentle pipetting. Peptides for LC/MS-MS were prepared following a method designed by Dr. Adam Carroll (Joint Mass Spectrometry Facility, The Research School of Chemistry, The Australian National University). Briefly, EV proteins were reduced with a final concentration of $10 \mathrm{mM}$ dithiothreitol (DTT) and alkylated with $30 \mathrm{mM}$ iodoacetamide (IAA). SDS was removed using a salty acetone precipitation: ice-cold acetone and $30 \mathrm{mM} \mathrm{NaCl}$ (final concentration) was used to pellet proteins by centrifugation. Pellets were washed with ice-cold acetone and resuspended in ammonium bicarbonate using sonication. $160 \mathrm{ng}$ of MS-grade trypsin (Pierce $^{\mathrm{TM}}$, ThermoFisher Scientific) was used to digest proteins overnight at $37{ }^{\circ} \mathrm{C}$. Excess ammonium bicarbonate was evaporated and the peptides resuspended in $0.1 \%(\mathrm{v} / \mathrm{v})$ formic acid (FA). Non-ionic detergents and salts were removed using strong cation exchange ZipTip ${ }_{\text {scx }}$ pipette tips (Merck Millipore) following the manufacturer's instructions. Peptide eluent from ZipTip elution was evaporated and the peptides resuspended in $0.1 \%$ FA for analysis by LC-MS/MS.

To allow qualitative presence/absence comparison be made with EV samples, soluble secreted protein (SS) and cell lysate samples (CL) were also prepared for LC-MS/ MS following the described procedure. For the SS samples, the supernatant from ultracentrifugation of culture filtrate at $100,000 \times g$ was collected and centrifuged twice at $120,000 \times g$ for $2 \mathrm{~h}$ to remove residual EVs and insoluble debris. Cell lysate samples were prepared from the cell pellets of culture used for EV isolation. Cell pellets were washed twice with $1 \mathrm{X}$ PBS $\mathrm{pH}$ 7.4 before grinding tissue in $\mathrm{LN}_{2}$ with a mortar and pestle and solubilising proteins in total protein buffer $(20 \mathrm{mM}$ Hepes- $\mathrm{NaOH}$ pH 7.4, $150 \mathrm{mM} \mathrm{NaCl}, 5 \mathrm{mM}$ EDTA, 3\% SDS, $1 \mathrm{mM}$ PMSF, $2 \mathrm{mM}$ DTT). Soluble supernatant and CL samples were prepared as above for LC-MS/MS except the digested peptides of $C L$ samples were passed through an Amicon centrifugal concentrator (MWCO $30 \mathrm{kDa}$; prewashed with $50 \%$ methanol and $\mathrm{dH}_{2} \mathrm{O}$ ) to remove residual nucleic acids, before removing excess ammonium bicarbonate as described above.

\section{LC-MS/MS}

Typically, $10 \mu \mathrm{L}$ of sample was injected into the LC-MS/ MS system consisting of a Dionex UltiMate 3000 Rapid Separation LC (RSLC) system with an Orbitrap Fusion or Q Exactive Plus Orbitrap (Thermo Scientific). Peptides were trapped using an Acclaim PepMap100 C18 Trap column (Thermo Scientific) at a flow rate of $15 \mu \mathrm{L} /$ min using $0.1 \%$ formic acid/2\% acetonitrile in $\mathrm{H}_{2} \mathrm{O}$ (solvent A). Peptides were eluted from the trap column to an in-house packed column $(75 \mu \mathrm{m}$ inner diameter (ID) $\times 25 \mathrm{~cm} ; 1.9 \mu \mathrm{m}$ C18 media, Dr Maisch) with a pulled tip emitter. Peptides were eluted from the column using a linear 100 -min gradient from $5 \%$ to $40 \%$ solvent B ( $0.1 \%$ formic acid $/ 80 \%$ acetonitrile). Data was collected in positive mode and full spectra acquired from $\mathrm{m} / \mathrm{z} 350$ to 2000 , with a resolution of 70,000 . For MS/MS, the top 15 most intense precursor ions were fragmented and ionised, and MS/MS spectra with $\mathrm{m} / \mathrm{z} 350-1750$ and resolution 17,500 recorded.

\section{Analysis of LC/MS-MS data}

SearchGUI v 3.3.17 was used to perform a high-sensitivity peptide search of raw MS/MS data files against a database of predicted protein sequences from $Z$. tritici WAI332 gene models $(\mathrm{n}=15,019$, (Wang et al., in review), with a target-decoy search strategy. SearchGUI was run with the search engines OMSSA, X! Tandem and MS-GF+, a peptide tolerance of $20 \mathrm{ppm}$, a fragment ion mass tolerance of $0.5 \mathrm{Da}$ and maximum FDR threshold of $1 \%$ [62]. Other parameters were: oxidised methionine and $\mathrm{N}$-terminal acetylation were allowed variable protein modifications; carbidomethylation of cysteines was an allowed fixed modification. Results were analysed using PeptideShaker v 1.16.44 [63]. Matches to contaminants, decoy sequences, 'doubtful matches' and matches with $\leq 2$ unique peptides were excluded. Proteins detected in $\geq 2 / 3$ replicates of at least one condition per experiment were included for analysis. Proteins were assigned functional annotations using InterProScan v5.0, run with default parameters [64] and blastP searches against the fungal $\mathrm{nr}$ and UniprotKB/Swissprot protein databases. SignalP 5.0 was used to identify proteins with canonical signal peptides [65]. Cazymes were identified with the dbCAN2 metaserver [66], proteases identified by searching sequences against the MEROPs database (release 11.0) [67] (non-peptidase homologue hits were excluded) and effectors predicted using EffectorP v 1.0 and $\mathrm{v} 2.0$ [68]. Membrane-associated proteins were defined using TMHMM v 2.0 and Pred-GPI $[69,70]$.

\section{Grouping fungal EV proteins in orthogroups}

Protein sequences from previous fungal EV studies were downloaded from Uniprot or Ensembl fungi and 
duplicate sequences within a species removed. Proteins were grouped into orthogroups using OrthoFinder v 2.3.11 [71], which was run with blastp for all-vs-all sequence searches (default parameters) and the multiple sequence alignment (msa) method for gene tree inference (using MAFFT and fasttree). Results were plotted using ggplot2 and the ComplexHeatmap packages in R.

\section{Supplementary information}

Supplementary information accompanies this paper at https://doi. org/10.1186/s40694-020-00103-2.

Additional file 1: Figure S1. EVs are produced by Z. tritici cultured in multiple growth media and by at least two Australian strains of Z. tritici, WAI332 and WAI321. TEM data shows EVs isolated from Z. tritici WAI332 cultures grown in (A) Fries 3, (B) minimal medium and (C) potato dextrose broth. (D) TEM imaging of Z. tritici WAI321 EVs isolated from Fries 3 growth medium. All samples were stained with $2 \%$ uranyl acetate and visualised with a Hitachi H7100FA TEM at 100 kV. Images were cropped and scale bars added with ImageJ; images were not modified otherwise. Figure S2. A Z. tritici protein, ZtSur7, is homologous to the proposed C. albicans EV marker, CaSur7. (a) An amino acid sequence alignment of ZtSur7 with CaSur7, which share a SUR7 domain, 4 transmembrane domains (TMD) and putative cytoplasmic/extracellular domains. (b) Illumina RNA-seq reads (pink) from wheat infected with $Z$. tritici WAI332 aligned to the WAI332 genomic region encoding ZtSur7, showing expression of $Z$. tritici Sur7 homologue (ZtSur7) in planta at 9 and 14 days post infection (dpi). Alignment coverage across the gene model is shown in grey in the top panel, while the gene model and a corresponding schematic are shown in blue.

Additional file 2: Table S1. Metadata for EV samples/fungal cultures presented in Fig. 1 and Fig. 2. Table S2. List of proteins identified in $\geq 4 / 5$ biological replicate samples of Z. tritici WAI332 EVs. Table S3. List of proteins identified in $\geq 2 / 3$ SS samples, with at least 2 unique peptides detected using LC-MS/MS. Proteins found in the SS samples and also in EVs are indicated. Table S4. List of Z. tritici WAI332 EV proteins predicted to be effectors by EffectorP. Proteins were included when predicted as effectors by both EffectorP v1.0 and V2.0. Table S5a. List of studies used to source fungal EV proteins to define orthogroups with Orthofinder. Table S5b. Summary of proteins used for Orthofinder analysis. Table S6. OrthoFinder output showing fungal EV proteins grouped by orthogroup (OG) and species. Uniprot-KB or ensembl protein names are followed by a species 'code' defined for Orthofinder. $C A A L=C$. albicans; $C R N E=C$. neoformans, $\mathrm{FOTG}=$ F. oxysporum f. sp. vasinfectum; $\mathrm{HICA}=H$. capsulatum; $\mathrm{PABR}=P$. brasiliensis; $\mathrm{SACE}=$ S. cerevisiae; $\mathrm{ZYTR}=$ Z. tritici. Table $\mathbf{S 7}$. List of proteins identified with $\geq 2$ unique peptides in $\geq 4 / 5$ cell lysate $(C L)$ samples $(n=533)$. Table S8. Potential Z. tritici WAI332 homologues for C. albicans EV marker proteins defined by Dawson et al., (2020). Homologous proteins were identified using reciprocal blastp searches of marker proteins against predicted proteins encoded in the Z $Z$. tritici WAl332 genome. Table S9. This data was generated by Orthofinder ( $v$ 2.3.11), using EV proteins described in previous fungal EV studies. Protein sequences were downloaded from Uniprot or Ensembl fungi and duplicate sequences removed within each species. Information on the studies listed and the proteins from each species is shown in Table S5.

\section{Acknowledgements}

The authors acknowledge the facilities and the scientific and technical assistance of Microscopy Australia at the Advanced Imaging Precinct, The Australian National University, a facility that is funded by the University and State and Federal Governments. Particular acknowledgement goes to Dr. Melanie Rug and Joanne Lee for their support and technical advice. The authors also acknowledge the facilities and technical support from Dr Adam Carroll and Joseph Boileau at the Joint Mass Spectrometry Facility at the Research School of Chemistry, The Australian National University.

\section{Authors' contributions}

$\mathrm{EHH}$ and PSS designed and conceived the research. EH conducted the experiments and prepared the first draft of the manuscript. EH and PSS wrote the final versions of the manuscript. Both authors read and approved the final manuscript.

\section{Funding}

EHH was supported by an Australian Government Research Training Program (RTP) Scholarship and a Grains Research and Development Corp. (GRDC) Grains Research Scholarship (GRS).

\section{Availability of data and materials}

The datasets used and/or analysed during the current study are available from the corresponding author on reasonable request.

\section{Ethics approval and consent to participate}

Not applicable.

\section{Consent for publication}

Not applicable.

\section{Competing interests}

The authors declare that they have no competing interests.

Received: 1 July 2020 Accepted: 11 September 2020

Published online: 18 September 2020

\section{References}

1. Jørgensen LN, Hovmøller MS, Hansen JG, Lassen P, Clark B, Bayles R, Rodemann B, Flath K, Jahn M, Goral T, et al. IPM strategies and their dilemmas including an introduction to http://www.eurowheat.org. J Integr Agric. 2014;13:265-81.

2. Fones $\mathrm{H}$, Gurr $\mathrm{S}$. The impact of septoria tritici blotch disease on wheat: an EU perspective. Fungal Genet Biol. 2015;79:3-7.

3. Kema G. Histology of the pathogenesis of Mycosphaerella graminicola in wheat. Phytopathology. 1996;86:777.

4. Duncan KE, Howard RJ. Cytological analysis of wheat infection by the leaf blotch pathogen Mycosphaerella graminicola. Mycol Res. 2000;104:1074-82.

5. Rudd JJ, Kanyuka K, Hassani-Pak K, Derbyshire M, Andongabo A, Devonshire J, Lysenko A, Saqi M, Desai NM, Powers SJ, et al. Transcriptome and metabolite profiling of the infection cycle of Zymoseptoria tritici on wheat reveals a biphasic interaction with plant immunity involving differential pathogen chromosomal contributions and a variation on the hemibiotrophic lifestyle definition. Plant Physiol. 2015;167:1158-85.

6. Wang $M$, Weiberg $A$, Jin H. Pathogen small RNAs: a new class of effectors for pathogen attacks. Mol Plant Pathol. 2015;16:219-23.

7. Morais do Amaral A, Antoniw J, Rudd JJ, Hammond-Kosack KE. Defining the predicted protein secretome of the fungal wheat leaf pathogen Mycosphaerella graminicola. PLOS ONE. 2012;7:1-19.

8. Plissonneau C, Hartmann FE, Croll D. Pangenome analyses of the wheat pathogen Zymoseptoria tritici reveal the structural basis of a highly plastic eukaryotic genome. BMC Biol. 2018;16:5.

9. Zhong Z, Marcel TC, Hartmann FE, Ma X, Plissonneau C, Zala M, Ducasse A, Confais J, Compain J, Lapalu N, et al. A small secreted protein in Zymoseptoria tritici is responsible for avirulence on wheat cultivars carrying the Stb6 resistance gene. N Phytol. 2017;214:619-31.

10. Mirzadi Gohari A, Ware SB, Wittenberg AH, Mehrabi R, Ben M'Barek S, Verstappen EC, van der Lee TA, Robert O, Schouten HJ, de Wit PP, et al. Effector discovery in the fungal wheat pathogen Zymoseptoria tritici. Mol Plant Pathol. 2015;16:931-45.

11. Marshall R, Kombrink A, Motteram J, Loza-Reyes E, Lucas J, HammondKosack KE, Thomma BP, Rudd JJ. Analysis of two in planta expressed LysM effector homologs from the fungus Mycosphaerella graminicola reveals novel functional properties and varying contributions to virulence on wheat. Plant Physiol. 2011;156:756-69.

12. McDonald MC, McDonald BA, Solomon PS. Recent advances in the Zymoseptoria tritici-wheat interaction: insights from pathogenomics. Front Plant Sci. 2015;6:1-5. 
13. Meile L, Croll D, Brunner PC, Plissonneau C, Hartmann FE, McDonald BA, Sanchez-Vallet A. A fungal avirulence factor encoded in a highly plastic genomic region triggers partial resistance to septoria tritici blotch. $\mathrm{N}$ Phytol. 2018;219:1048-61.

14. Stewart EL, Croll D, Lendenmann MH, Sanchez-Vallet A, Hartmann FE, Palma-Guerrero J, Ma X, McDonald BA. Quantitative trait locus mapping reveals complex genetic architecture of quantitative virulence in the wheat pathogen Zymoseptoria tritici. Mol Plant Pathol. 2018;19:201-16.

15. Liu T, Song T, Zhang X, Yuan H, Su L, Li W, Xu J, Liu S, Chen L, Chen T, et al. Unconventionally secreted effectors of two filamentous pathogens target plant salicylate biosynthesis. Nat Commun. 2014;5:4686.

16. Ridout CJ, Skamnioti P, Porritt O, Sacristan S, Jones JD, Brown JK. Multiple avirulence paralogues in cereal powdery mildew fungi may contribute to parasite fitness and defeat of plant resistance. Plant Cell. 2006;18:2402-14.

17. Giraldo MC, Dagdas YF, Gupta YK, Mentlak TA, Yi M, Martinez-Rocha AL, Saitoh H, Terauchi R, Talbot NJ, Valent B. Two distinct secretion systems facilitate tissue invasion by the rice blast fungus Magnaporthe oryzae. Nat Commun. 2013;4:1996.

18. Wang S, Boevink PC, Welsh L, Zhang R, Whisson SC, Birch PRJ. Delivery of cytoplasmic and apoplastic effectors from Phytophthora infestans haustoria by distinct secretion pathways. N Phytol. 2017;216:205-15.

19. Ben M'Barek S, Cordewener JH, van der Lee TA, America AH, Mirzadi Gohari A, Mehrabi R, Hamza S, de Wit PJ, Kema GH. Proteome catalog of Zymoseptoria tritici captured during pathogenesis in wheat. Fungal Genet Biol. 2015;79:42-53.

20. Yang F, Li W, Derbyshire M, Larsen MR, Rudd JJ, Palmisano G. Unraveling incompatibility between wheat and the fungal pathogen Zymoseptoria tritici through apoplastic proteomics. BMC Genomics. 2015;16:362.

21. van Niel G, D'Angelo G, Raposo G. Shedding light on the cell biology of extracellular vesicles. Nat Rev Mol Cell Biol. 2018;19:213-28.

22. Colombo M, Moita C, van Niel G, Kowal J, Vigneron J, Benaroch P, Manel N, Moita LF, Thery C, Raposo G. Analysis of ESCRT functions in exosome biogenesis, composition and secretion highlights the heterogeneity of extracellular vesicles. J Cell Sci. 2013;126:5553-65.

23. Cai Q, Qiao L, Wang M, He B, Lin FM, Palmquist J, Huang SD, Jin H. Plants send small RNAs in extracellular vesicles to fungal pathogen to silence virulence genes. Science. 2018;360:1126-9.

24. Rutter BD, Innes RW. Extracellular vesicles as key mediators of plantmicrobe interactions. Curr Opin Plant Biol. 2018;44:16-22.

25. Rutter BD, Innes RW. Extracellular vesicles isolated from the leaf apoplast carry stress-response proteins. Plant Physiol. 2017;173:728-41.

26. Baldrich P, Rutter BD, Karimi HZ, Podicheti R, Meyers BC, Innes RW. Plant extracellular vesicles contain diverse small RNA species and are enriched in 10- to 17-nucleotide "tiny" RNAs. Plant Cell. 2019;31:315-24.

27. Regente M, Pinedo M, San Clemente H, Balliau T, Jamet E, de la Canal L. Plant extracellular vesicles are incorporated by a fungal pathogen and inhibit its growth. J Exp Bot. 2017;68:5485-95.

28. Zhao K, Bleackley M, Chisanga D, Gangoda L, Fonseka P, Liem M, Kalra H, Al Saffar H, Keerthikumar S, Ang CS, et al. Extracellular vesicles secreted by Saccharomyces cerevisiae are involved in cell wall remodelling. Commun Biol. 2019;2:305

29. Oliveira DL, Nakayasu ES, Joffe LS, Guimaraes AJ, Sobreira TJ, Nosanchuk JD, Cordero RJ, Frases S, Casadevall A, Almeida IC, et al. Characterization of yeast extracellular vesicles: evidence for the participation of different pathways of cellular traffic in vesicle biogenesis. PLoS ONE. 2010;5:e11113.

30. Bielska E, May RC. Extracellular vesicles of human pathogenic fungi. Curr Opin Microbiol. 2019;52:90-9.

31. Rodrigues ML, Nakayasu ES, Oliveira DL, Nimrichter L, Nosanchuk JD, Almeida IC, Casadevall A. Extracellular vesicles produced by Cryptococcus neoformans contain protein components associated with virulence. Eukaryot Cell. 2008;7:58-67.

32. Bleackley MR, Samuel M, Garcia-Ceron D, McKenna JA, Lowe RGT, Pathan M, Zhao K, Ang CS, Mathivanan S, Anderson MA. Extracellular vesicles from the cotton pathogen Fusarium oxysporum f. sp. vasinfectum induce a phytotoxic response in plants. Front Plant Sci. 2020;10:1610

33. Bachurski D, Schuldner M, Nguyen PH, Malz A, Reiners KS, Grenzi PC, Babatz F, Schauss AC, Hansen HP, Hallek M, et al. Extracellular vesicle measurements with nanoparticle tracking analysis_an accuracy and repeatability comparison between NanoSight NS300 and ZetaView. J Extracell Vesicles. 2019;8:1596016.
34. Paper JM, Scott-Craig JS, Adhikari ND, Cuomo CA, Walton JD. Comparative proteomics of extracellular proteins in vitro and in planta from the pathogenic fungus Fusarium graminearum. Proteomics. 2007;7:3171-83.

35. Nombela C, Gil C, Chaffin WL. Non-conventional protein secretion in yeast. Trends Microbiol. 2006;14:15-21.

36. Yang $F$, Yin Q. Comprehensive proteomic analysis of the wheat pathogenic fungus Zymoseptoria tritici. Proteomics. 2016;16:98-101.

37. Bleackley MR, Dawson CS, Anderson MA. Fungal extracellular vesicles with a focus on proteomic analysis. Proteomics. 2019;1800232:1-14.

38. Tomas A, Feng GH, Reeck GR, Bockus WW, Leach JE. Purification of a cultivar-specific toxin from Pyrenophora tritici-repentis, causal agent of Tan Spot of wheat. Mol Plant Microbe Interact. 1990;3:221-4.

39. Phan CS, Li H, Kessler S, Solomon PS, Piggott AM, Chooi YH, Bipolenins K-N. New sesquiterpenoids from the fungal plant pathogen Bipolaris sorokiniana. Beilstein J Org Chem. 2019;15:2020-8.

40. Dawson CS, Garcia-Ceron D, Rajapaksha H, Faou P, Bleackley MR, Anderson MA. Protein markers for Candida albicans EVs include claudin-like Sur7 family proteins. J Extracell Vesicles. 2020;9:1750810.

41. Thery C, Witwer KW, Aikawa E, Alcaraz MJ, Anderson JD, Andriantsitohaina R, Antoniou A, Arab T, Archer F, Atkin-Smith GK, et al. Minimal information for studies of extracellular vesicles 2018 (MISEV2018): a position statement of the International Society for Extracellular Vesicles and update of the MISEV2014 guidelines. J Extracell Vesicles. 2018;7:1535750

42. Albuquerque PC, Nakayasu ES, Rodrigues ML, Frases S, Casadevall A, Zancope-Oliveira RM, Almeida IC, Nosanchuk JD. Vesicular transport in Histoplasma capsulatum: an effective mechanism for trans-cell wall transfer of proteins and lipids in ascomycetes. Cell Microbiol. 2008;10:1695-710.

43. Bitencourt TA, Rezende CP, Quaresemin NR, Moreno P, Hatanaka O, Rossi A, Martinez-Rossi NM, Almeida F. Extracellular vesicles from the dermatophyte Trichophyton interdigitale modulate macrophage and keratinocyte functions. Front Immunol. 2018;9:2343.

44. Silva VKA, Rodrigues ML, May RC. Deciphering fungal extracellular vesicles: from cell biology to pathogenesis. Curr Clin Microbiol Rep. 2019;6:89-97.

45. Kowal J, Arras G, Colombo M, Jouve M, Morath JP, Primdal-Bengtson B, Dingli F, Loew D, Tkach M, Thery C. Proteomic comparison defines novel markers to characterize heterogeneous populations of extracellular vesicle subtypes. PNAS. 2016;113:E968-77.

46. Kaplan A, Bueno M, Fournier AE. Extracellular functions of 14-3-3 adaptor proteins. Cell Signal. 2017;31:26-30.

47. Wolf JM, Espadas J, Luque-Garcia J, Reynolds T, Casadevall A. Lipid biosynthetic genes affect Candida albicans extracellular vesicle morphology, cargo, and immunostimulatory properties. Eukaryot Cell. 2015;14:745-54.

48. Vallejo MC, Nakayasu ES, Matsuo AL, Sobreira TJ, Longo LV, Ganiko L, Almeida IC, Puccia R. Vesicle and vesicle-free extracellular proteome of Paracoccidioides brasiliensis: comparative analysis with other pathogenic fungi. J Proteome Res. 2012;11:1676-85.

49. Vargas G, Rocha JD, Oliveira DL, Albuquerque PC, Frases S, Santos SS, Nosanchuk JD, Gomes AM, Medeiros LC, Miranda K, et al. Compositional and immunobiological analyses of extracellular vesicles released by Candida albicans. Cell Microbiol. 2015;17:389-407.

50. Perincherry L, Lalak-Kanczugowska J, Stepien L. Fusarium-produced mycotoxins in plant-pathogen interactions. Toxins. 2019;11:664.

51. Kucharzewska P, Belting M. Emerging roles of extracellular vesicles in the adaptive response of tumour cells to microenvironmental stress. J Extracell Vesicles. 2013;2:20304.

52. Zarnowski R, Sanchez H, Covelli AS, Dominguez E, Jaromin A, Bernhardt J, Mitchell KF, Heiss C, Azadi P, Mitchell A, et al. Candida albicans biofilminduced vesicles confer drug resistance through matrix biogenesis. PLoS Biol. 2018;16:e2006872.

53. Cleare LG, Zamith D, Heyman HM, Couvillion SP, Nimrichter L, Rodrigues ML, Nakayasu ES, Nosanchuk JD. Media Matters! Alterations in the loading and release of Histoplasma capsulatum extracellular vesicles in response to different nutritional milieus. Cell Microbiol. 2020;22:e13217.

54. Steinberg G. Cell biology of Zymoseptoria tritici: pathogen cell organization and wheat infection. Fungal Genet Biol. 2015;79:17-23.

55. Francisco CS, Ma X, Zwyssig MM, McDonald BA, Palma-Guerrero J. Morphological changes in response to environmental stresses in the fungal plant pathogen Zymoseptoria tritici. Sci Rep. 2019;9:9642. 
56. Wang HX, Douglas LM, Aimanianda V, Latge JP, Konopka JB. The Candida albicans Sur7 protein is needed for proper synthesis of the fibrillar component of the cell wall that confers strength. Eukaryot Cell. 2011;10:72-80.

57. Young ME, Karpova TS, Brugger B, Moschenross DM, Wang GK, Schneiter R, Wieland FT, Cooper JA. The Sur7p family defines novel cortical domains in Saccharomyces cerevisiae, affects sphingolipid metabolism, and is involved in sporulation. Mol Cell Biol. 2002;22:927-34.

58. Alvarez FJ, Douglas LM, Rosebrock A, Konopka JB. The Sur7 protein regulates plasma membrane organization and prevents intracellular cell wall growth in Candida albicans. Mol Biol Cell. 2008;19:5214-25.

59. Rodrigues ML, Nimrichter L, Oliveira DL, Frases S, Miranda K, Zaragoza O, Alvarez M, Nakouzi A, Feldmesser M, Casadevall A. Vesicular polysaccharide export in Cryptococcus neoformans is a eukaryotic solution to the problem of fungal trans-cell wall transport. Eukaryot Cell. 2007;6:48-59.

60. Théry C, Amigorena S, Raposo G, Clayton A: Isolation and characterisation of exosomes from cell culture supernatants and biological fluids. Curr Protoc Cell Biol 2006;30:3.22.21-23.22.29.

61. Wickham H. ggplot2: elegant graphics for data analysis. New York: Springer; 2016

62. Barsnes H, Vaudel M. SearchGUI: a highly adaptable common interface for proteomics search and de novo engines. J Proteome Res. 2018;17:2552-5.

63. Vaudel M, Burkhart JM, Zahedi RP, Oveland E, Berven FS, Sickmann A, Martens L, Barsnes H. PeptideShaker enables reanalysis of MS-derived proteomics data sets. Nat Biotechnol. 2015;33:22-4.

64. Jones P, Binns D, Chang HY, Fraser M, Li W, MCAnulla C, McWilliam H, Maslen J, Mitchell A, Nuka G, et al. InterProScan 5: genome-scale protein function classification. Bioinformatics. 2014;30:1236-40.
65. Almagro Armenteros JJ, Tsirigos KD, Sonderby CK, Petersen TN, Winther $\mathrm{O}$, Brunak S, von Heijne G, Nielsen H. SignalP 5.0 improves signal peptide predictions using deep neural networks. Nat Biotechnol. 2019;37:420-3.

66. Zhang $H$, Yohe T, Huang L, Entwistle S, Wu P, Yang Z, Busk PK, Xu Y, Yin Y. dbCAN2: a meta server for automated carbohydrate-active enzyme annotation. Nucleic Acids Res. 2018;46:W95-101.

67. Rawlings ND, Barrett AJ, Thomas PD, Huang X, Bateman A, Finn RD. The MEROPS database of proteolytic enzymes, their substrates and inhibitors in 2017 and a comparison with peptidases in the PANTHER database. Nucleic Acids Res. 2018;46:D624-32.

68. Sperschneider J, Dodds PN, Gardiner DM, Singh KB, Taylor JM. Improved prediction of fungal effector proteins from secretomes with EffectorP 2.0. Mol Plant Pathol. 2018;19:2094-110.

69. Krogh A, Larsson B, von Heijne G, Sonnhammer ELL. Predicting transmembrane protein topology with a hidden markov model: application to complete genomes. J Mol Biol. 2001;305:567-80.

70. Pierleoni A, Martelli P, Casadio R. PredGPI: a GPI-anchor predictor. BMC Bioinformatics. 2008;9:392.

71. Emms DM, Kelly S. OrthoFinder: phylogenetic orthology inference for comparative genomics. Genome Biol. 2019;20:238

\section{Publisher's Note}

Springer Nature remains neutral with regard to jurisdictional claims in published maps and institutional affiliations.
Ready to submit your research? Choose BMC and benefit from:

- fast, convenient online submission

- thorough peer review by experienced researchers in your field

- rapid publication on acceptance

- support for research data, including large and complex data types

- gold Open Access which fosters wider collaboration and increased citations

- maximum visibility for your research: over $100 \mathrm{M}$ website views per year

At BMC, research is always in progress.

Learn more biomedcentral.com/submissions 